\title{
SCREENING, CHARACTERIZATION, AND IN VITRO EVALUATION OF PROBIOTIC PROPERTIES OF LACTOBACILLUS STRAINS
}

\author{
NEHA JAIN*, ARCHANA MEHTA, VANDANA BHARTI
}

Department of Botany, Laboratory of Molecular Biology, Dr. H. S. Gour Central University, Sagar - 470 003, Madhya Pradesh, India. Email: nehaj147@gmail.com

Received: 21 July 2017, Revised and Accepted: 12 May 2017

\section{ABSTRACT}

Objective: The aim of the present investigation was to isolate and identify Lactobacillus strains from dairy and cattle dung samples. Potent isolates were selected for screening by antimicrobial activity; selected lactobacilli were further tested for probiotic properties and adhesive attributes.

Methods: Lactobacilli were isolated aseptically on specific de man, rogosa and sharpe medium from dairy and cattle dung samples. Isolates were identified by Gram-staining, motility, catalase, endospore, and carbohydrate fermentation tests. Further, the isolates were screened for antimicrobial activity by disk diffusion assay, and potent lactobacilli were observed for probiotic properties: Acid and bile salt tolerance, gelatinase activity, and autolytic activity. For analyzing the adhesive attributes, isolates were observed for autoaggregation, coaggregation and microbial adhesion to solvents assay.

Results: About 12 Lactobacillus strains among 98 isolates exhibited maximum antimicrobial activity were further selected for identifying their probiotic and adhesive attributes. Among 12 selected isolates, cell-free supernatant (CFS) of buffalo milk BM10 and goat milk GM10 showed excellent antimicrobial activity, $20.34 \pm 0.02 \mathrm{~mm}$ against Staphylococcus aureus and $18.65 \pm 0.11 \mathrm{~mm}$ against Escherichia coli. Isolates showed survival at pH 2 and 3 and can tolerate $0.2-0.3 \%$ bile salt concentrations. The GM5 showed maximum autoaggregation (67.04 $\pm 0.61 \%)$ and minimum coaggregation $(11.51 \pm 0.50 \%)$ showed by GM3. The BM10 exhibited maximum adherent value $64.84 \pm 1.41 \%$ for $n$-hexadecane.

Conclusion: The two lactobacilli, BM10 and GM10 identified as Lactobacillus fermentum and Lactobacillus pentosus on the basis of phenotypic and sugar utilization tests. The CFS of both lactobacilli can be used as antimicrobial agent. Both isolates showed significant results of probiotic and adhesive attributes, therefore, can be evaluated for clinical and therapeutic applications.

Keywords: Lactobacillus, Antimicrobial, Probiotic, Adhesive properties

(c) 2017 The Authors. Published by Innovare Academic Sciences Pvt Ltd. This is an open access article under the CC BY license (http://creativecommons. org/licenses/by/4. 0/) DOI: http://dx.doi.org/10.22159/ajpcr.2017.v10i8.14233

\section{INTRODUCTION}

The word "probiotic" originates from Greek verbal "pro bios" which means "for life" contrasting to "antibiotics" which means "against life." Probiotics have recently emerged as the most powerful food grade microbial agents comprise the ability to express numerous health promoting functions of considerable commercial value and therapeutic potential. These are live microorganisms, when administered in adequate amounts confer several health benefits on the host [1], which includes improving cholesterol assimilation [2], lactose tolerance [3], anti-inflammatory [4], antioxidative [5], anticancer [6], antidiarrheal [7], antiallergic [8], antidiabetic [9], antihypertensive effects [10], controlling obesity [11], and also helps in mineral absorption [12]. Probiotics received generally-regarded-as-safe status, due to its safety profile. Lactic acid bacteria (LAB) also enhance the stability and nutritional value of food products by preventing the growth of pathogenic and spoilage microbes [13]. Among LAB, Lactobacilli is the largest genus which found symbiotically in our gut. General mechanism of probiotics includes inhibition of pathogens through compete for nutrients and adhesive sites [14]. LAB produces compound like bacteriocins, which causes direct antagonism [15] and boost up the immune system [16]. The prerequisite conditions for a probiotic strain to establish in the market are: must be compete with gut microflora, acid tolerant, and bile salt tolerant as during transit from gut; these have to survive in high acidic environment and bile salt concentration and must have adherent potential. The present work aimed to isolate, identify, characterize, and evaluate the probiotic potential of lactobacilli from dairy and cattle dung samples. Subsequently, the isolates were screened for antimicrobial potential.
Autoaggregation, coaggregation, and microbial adhesion to solvents (MATS) properties were evaluated for assessing the ability of isolates for adhesive attributes.

\section{METHODS}

Isolation and maintenance of probiotic bacteria

About 1g of solid (cattle dung and cheese) homogenized sample and $1 \mathrm{ml}$ of liquid (dairy) sample were mixed with $9 \mathrm{ml}$ of sterile saline $(0.85 \% \mathrm{NaCl})$, samples were serially diluted, and proper dilutions were pour plated on de man, rogosa and sharpe (MRS) agar. The plates were incubated at $37^{\circ} \mathrm{C}$ for $24 \mathrm{hrs}$ in an anaerobic $\mathrm{CO}_{2}$ Jar (Himedia, India). Single isolated colonies were picked up and purified by repeated streaking. The selected colonies were maintained in MRS agar slants $\left(0.8 \%\right.$ agar) at $4^{\circ} \mathrm{C}$. In addition, $0.05 \%$ cysteine was added in MRS medium for improving its specificity of isolation of lactobacilli [17].

\section{Preliminary identification of the isolates}

Identification of the isolates at genus level was carried out using morphological, phenotypic, and biochemical methods. The cultures were examined microscopically for Gram-staining and endospore test by using Himedia, Kits (K006 and K001), respectively, according to manufacturer's instruction. Motility test was performed by hanging drop method and catalase test by using freshly prepared $3 \% \mathrm{H}_{2} \mathrm{O}_{2}$. The carbohydrate fermentation profiles of isolates were determined using KB002 Hiassorted ${ }^{\mathrm{TM}}$ biochemical test kit. Fermentation profiles of lactobacilli were interpreted by advanced bacterial identification Software. 
Antimicrobial activity

Antimicrobial activity of the lactobacilli isolates was checked by disk diffusion method. Isolates were screened against Bacillus subtilis MTCC 1143, Escherichia coli MTCC 433, Enterococcus faecalis MTCC 439, Pseudomonas aeruginosa MTCC 6642, and Staphylococcus aureus MTCC 9886, as the indicator microorganisms. Isolates were subcultured in sterile test tubes containing MRS broth at $37^{\circ} \mathrm{C}$ for $24 \mathrm{hrs}$ and transferred into a sterile flask containing $150 \mathrm{ml}$ MRS broth and the broth culture were incubated at $37^{\circ} \mathrm{C}$ for 3 days in thermostat water bath. The cell-free supernatant (CFS) was prepared by centrifuge the 3 days old cultures at $10000 \mathrm{rpm}$ for 20 minutes [18]. Test (indicator) microorganisms were grown in a nutrient broth at $37^{\circ} \mathrm{C}$ for $24 \mathrm{hrs}$. Streptomycin and Gentamycin were used as standard. Experiments were conducted in triplicates.

\section{Acid and bile salt tolerance}

Acid tolerances of selected lactobacilli were determined by the method described by Sieladie et al., [19]. Lactobacilli isolates were cultured for $6 \mathrm{hrs}$ in MRS broth at $37^{\circ} \mathrm{C} .100 \mathrm{ml}$ fresh MRS broth was prepared, and $\mathrm{pH}$ had been adjusted to 2,3 or $7 \mathrm{using} 1 \mathrm{~N} \mathrm{HCL}$ or $\mathrm{NaOH}$. Add $1 \mathrm{ml}$ of the $6 \mathrm{hrs}$ old culture in flasks. Optical density was recorded at $620 \mathrm{~nm}$ after 6 and 24 hrs incubation period at $37^{\circ} \mathrm{C}$. Surviving (\%) can be calculated by following formula:

$$
\text { Surviving }(\%)=\frac{\Delta \mathrm{DOpH} 7-\Delta \mathrm{DOpH} 2 \mathrm{or} 3}{\Delta \mathrm{DOpH} 7} \times 100
$$

A modified method given by Dora and Glenn [20] is used for estimation of bile salt tolerance in a similar method of acid tolerance. MRS broth supplemented with different concentration 0.2 and $0.4 \%$ of bile salts were used for the experiment. Surviving (\%) in bile salt can be calculated by following formula:

$$
\text { Surviving }(\%)=\frac{\Delta \mathrm{D} 00 \% \mathrm{BS}-\Delta \mathrm{D} 00.2 \text { or } 0.4 \% \mathrm{BS}}{\Delta \mathrm{DO} 0 \% \mathrm{BS}} \times 100
$$

\section{Gelatinase activity}

Gelatinase activity of lactobacilli isolates was determined by Harrigan and McCance [21] method. $2 \mu \mathrm{l}$ of a $6 \mathrm{hrs}$ old culture was spotinoculated into the nutrient gelatin agar (Himedia, India). The plates were incubated anaerobically for $48 \mathrm{hrs}$ at $37^{\circ} \mathrm{C}$ after which plates were submerged with saturated ammonium sulfate solution and observed for clear zones surrounding colonies (positive reaction for gelatin hydrolysis). A strain of $S$. aureus MTCC 9886 was used as positive control.

\section{Autoaggregation and coaggregation assay}

Autoaggregation was measured according to the method given by Basson et al. [22]. The lactobacilli strains were inoculated in MRS broth at $37^{\circ} \mathrm{C}$ for $24 \mathrm{hrs}$. The cells were then harvested $(7000 \mathrm{~g}, 10$ minutes, $20^{\circ} \mathrm{C}$ ), washed, resuspend in sterile physiological water and diluted to optical densities (OD) at $660 \mathrm{~nm}=0.3 .1 \mathrm{ml}$ of the cell suspension was transferred to a $2 \mathrm{ml}$ sterile plastic cuvette and the OD at $660 \mathrm{~nm}$ recorded over 60 minutes using a microplate reader (Cyber Elisa R01, Cyberlab USA). Autoaggregation was determined using the given equation:

$$
\text { Auto }- \text { aggregation } \%=\frac{O D(0)-O D(60)}{O D(0)} \times 100
$$

Where $\mathrm{OD}(0)$ and $\mathrm{OD}(60)$ are the initial and final OD recorded at 0 and after 60 minutes of incubation, respectively.

Coaggregation (\%) was determined similar autoaggregation method. Isolate culture and coaggregation partners were inoculated in $10 \mathrm{ml}$ MRS and MHA, respectively. Coaggregation (\%) is determined using the given equation:

$$
\text { Auto }- \text { aggregation } \%=\frac{\mathrm{OD}(\mathrm{Tot})-\mathrm{OD}(\mathrm{S})}{\mathrm{OD}(0)} \times 100
$$

Where $\mathrm{OD}$ (Tot) is the initial OD, taken immediately after the relevant strains were paired. OD(s) is the OD of the supernatant after 60 minutes. Experiments were conducted in triplicate.

\section{Autolytic assay}

The autolysis of isolates was measured according to the method given by Saran et al. [23]. The cell suspension was prepared same as for autoaggregation assays. The optical density was observed after 3 and $5 \mathrm{hrs}$ at $620 \mathrm{~nm}$. The percentage of autolytic activity was calculated by the following formula:

$$
\text { Autolyticactivity }=1-\frac{\mathrm{OD}_{\mathrm{t}}}{\mathrm{OD}_{0}} \times 100
$$

Where $\mathrm{OD}_{\mathrm{t}}$ represents the optical density after mixing in MRS at time $\mathrm{t}=3$ or 5 hrs and $\mathrm{OD}_{0}$ the optical density after mixing at $\mathrm{t}=0$.

\section{Microbial adhesion to solvents (MATS)}

MATS was measured according to the method given by Kos et al., [24]. The sample was prepared by centrifuged the bacterial culture at $5000 \mathrm{rpm}$ for 15 minutes, washed twice in PBS and resuspend in $0.1 \mathrm{~mol} \mathrm{KNO}_{3}(\mathrm{pH}$ 6.2). The absorbance of the cell suspension was recorded at $600 \mathrm{~nm}\left(\mathrm{~A}_{0}\right) .1 \mathrm{ml}$ solvent (xylene, toluene, and n-hexadecane) was added into $3 \mathrm{ml}$ cell suspension. After preincubation at room temperature, the two-phase system was developed, mixed it by vortexing for 2 minutes. The aqueous phase was removed after 20 minutes of incubation at room temperature and its absorbance at $600 \mathrm{~nm}\left(\mathrm{~A}_{1}\right)$ was measured. The percentage of bacterial adhesion to solvent was calculated as $\left(1-A_{1} / A_{0}\right)$. 100 . Experiments were carried out in triplicates.

\section{Statistical analysis}

Values were expressed as the mean \pm standard deviation, $\mathrm{n}=3$ and statistical analysis were carried out employing one-way ANOVA (completely randomized design) using Graph pad prism 7 (Inc., San Diego, CA, USA). Differences between the data were considered significant at $\mathrm{p}<0.05$.

\section{RESULTS AND DISCUSSION}

\section{Antimicrobial activity}

In the present study, out of 141 lactobacilli isolates, 94 isolated strains were nonmotile, Gram-positive, catalase-negative, rod-shaped; some were rods in chains and nonspore forming. These were coded according to their origin, and the results of carbohydrate fermentation profiles of 12 isolates were identified using biochemical tests and identified by advanced bacterial software which suggested that Lactobacillus casei and Lactobacillus fermentum were predominated lactobacilli (Table 1). 12 strains showed maximum antimicrobial activity (Fig. 1) were tested for evaluation of probiotic properties. The CFS of 12 exhibited strong antimicrobial activity against B. subtilis, E. coli, E. faecalis, P. aeruginosa, and $S$. aureus. The CFS of buffalo milk BM10: L. fermentum isolated from BM and goat milk GM10: Lactobacillus pentosus isolated from GM exhibited maximum antimicrobial potential. Among all 94 isolates, 20 isolates of cattle dung showed poor inhibition zone while isolates from GM exhibited strong antimicrobial potential. The CFS of GM10 showed zone of inhibition $(18.65 \pm 0.02 \mathrm{~mm})$ against $E$. coli and CFS of BM10 showed inhibition zone $(20.34 \pm 0.11 \mathrm{~mm})$ against $S$. aureus, while the standard antibiotics streptomycin and gentamycin showed $12 \pm 0.35 \mathrm{~mm}$ zone against $E$. coli and $10 \pm 0.3 \mathrm{~mm}$ zone against $S$. aureus. In a similar study, the culture supernatant of lactobacillus R1 strain showed a wide range of antimicrobial activity except against Aeromonas hydrophila ATCC 7966 [25]. Thus, the results of investigated study were better than standards and comparable with the results reported in the above study. Tested indicator pathogens generally cause food poisoning; thus, 


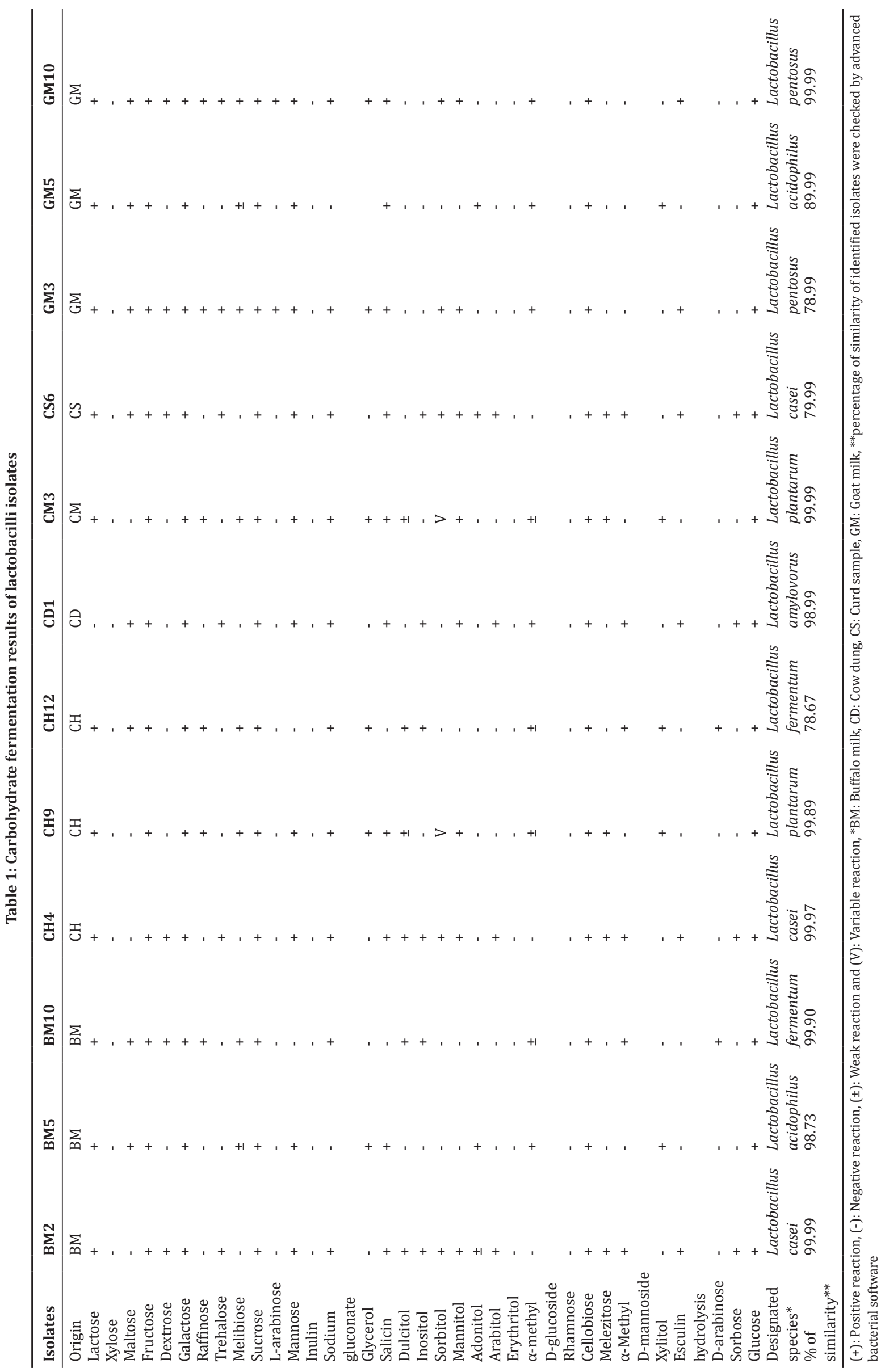


results suggested that the CFS of isolates can be used as antimicrobial agents.

\section{Acid tolerance}

To investigate the survival of lactobacilli isolates in the presence of acid and bile salt, their growth was observed at low $\mathrm{pH}$ ( 2 and 3 ) and at bile salt concentrations $(0.2 \%$ and $0.3 \%)$. Since, from entry into the mouth, to establish in the gut and colon, the LAB have to survive in acidic environment and bile salt presence which secrets in the liver. The stomach has low $\mathrm{pH}$ ranged from 1.5 to 3.5 , due to secretion of gastric juice and intestine is moderately alkaline, $\mathrm{pH}$ ranged from 8 to 8.5 . In the investigated study, results indicated that all 12 isolates exhibited a survival $<50 \%$, ranged from $56.93 \%$ to $80.88 \%$ at $\mathrm{pH} 2$ and $61.44 \%$ to $81.25 \%$ at $\mathrm{pH} 3$. According to the classification criteria, the survival percentage of isolates in acidic condition has been divided into four categories: Excellent if the isolate survived at pH 2 after 24 hrs; very good if the isolate survived at pH 2 after 6 hrs but not after 24 hrs; good if the isolate survived at $\mathrm{pH} 3$ after 24 hrs but not at $\mathrm{pH} 2$; poor if the isolate did not survive in any experimental condition. The results (Fig. 2) showed that out of 12 isolates, 3 isolates (BM10, curd sample (CS)5 and GM10) exhibited excellent growth in $\mathrm{pH} 2$ and 3, 4 isolates (BM5, CH12, GM3 and GM5) exhibited very good growth, 3 isolates (cow dung [CD]1, CH4 and CM3) exhibited good growth while 2 isolates (BM2 and CH9) exhibited poor survival at low pH. Singh et al. [26] reported the maximum acid tolerance of nine lactobacilli isolates ranged from $46.47 \%$ to 79.74 at $\mathrm{pH} 2$ and $46.70 \%$ to $102.48 \%$ at $\mathrm{pH} 3$.

\section{Bile salt tolerance}

Bacterial cell wall contains lipids and fatty acids, which disrupt in duodenal part of the gut by bile salts, as it has a detergent like nature. Hence, survival in bile salt than acidic environment is an important property of LAB, which facilitates it to efficiently perform their action in gut [27]. Isolates showed good survival in the presence of 0.2 and $0.4 \%$ bile salt varies from $36.65 \%$ to $79.91 \%$ in $0.2 \%$ bile salt concentration, while survival percentages on increasing bile salt concentration $0.4 \%$ decreased up to $30.41 \%$ and GM10 showed maximum $(61.59 \%)$ value of bile salt tolerance. Classification criteria of bile salt tolerance also have been divided into: Excellent if the isolate survived at $0.4 \%$ bile salt after $24 \mathrm{hrs}$; very good if the isolate survived at $0.4 \%$ bile salt after $6 \mathrm{~h}$ but not after $24 \mathrm{~h}$; good if the isolate survived at $0.2 \%$ bile salt after 24 hrs but not at $0.4 \%$ bile salt; poor if the isolate did not survive in any experimental condition. Among 12 isolates, two isolates (GM3 and GM10) exhibited an excellent survival, three isolates (BM10, $\mathrm{CH} 4$, and CS6) exhibited a very good survival of bile salt tolerance, and five isolates (BM2, BM5, CD1, CM3, and GM5) showed good survival while two isolates ( $\mathrm{CH} 9$ and $\mathrm{CH} 12$ ) showed poor bile salt tolerance (Fig. 3). The previous studies showed that Lactobacillus strains showed tolerance in $0.05-2.5 \%$ bile salt concentrations [28,29].

\section{Autolytic activity}

In this study, the autolysis rate of isolates measured in MRS medium after 3 and 5 hrs. GM3 showed the lowest value of autolytic activity $8.32 \pm 0.16 \%$ after $3 \mathrm{hrs}$ and $15.85 \pm 0.13 \%$ after $5 \mathrm{hrs}$. Saran et al. [23] evaluated the autolytic activity of Lactobacillus acidophilus 291 in the presence of honey and inulin; their observation suggests that the autolytic activity in MRS was approximately $9 \%$ after $3 \mathrm{hrs}$ and further reached to $12 \%$ after $5 \mathrm{hrs}$. However, in the presence of inulin the autolytic activity was reduced to $5.6-6.09 \%$. The results (Table 2) obtained in the present study are closely comparable to previous results reported in literature and in the presence of prebiotics like honey and inulin; autolytic activity of these isolates can also be improved. Autolysis is a spontaneous degeneration of bacterial cell due to age or unfavorable conditions. During autolysis intracellular enzymes release out of the cell, this property of lactobacilli is useful for cheese ripening as these enzymes help in texture and flavor improvement. An enzyme autolysin during autolysis activates which disrupt peptidoglycan subunits of the cell wall by hydrolyzing covalent bonds. It reduces the number of probiotic bacteria [30] and decreases adhesiveness.

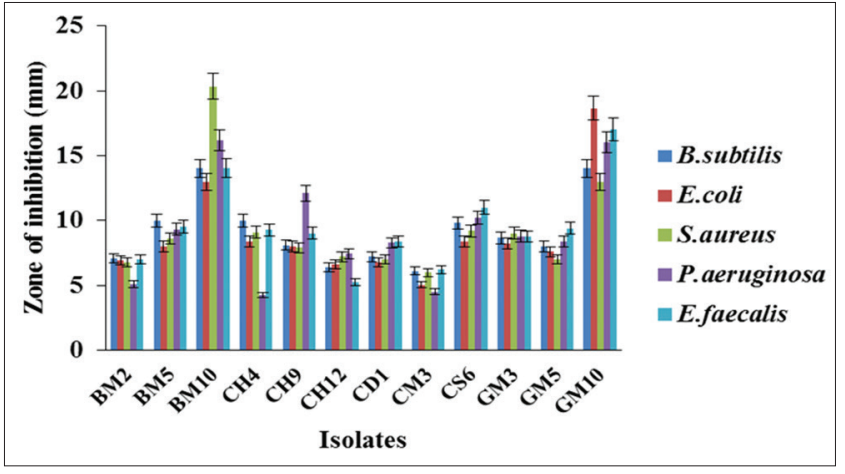

Fig. 1: Antimicrobial activity of cell-free supernatant of lactobacilli isolates

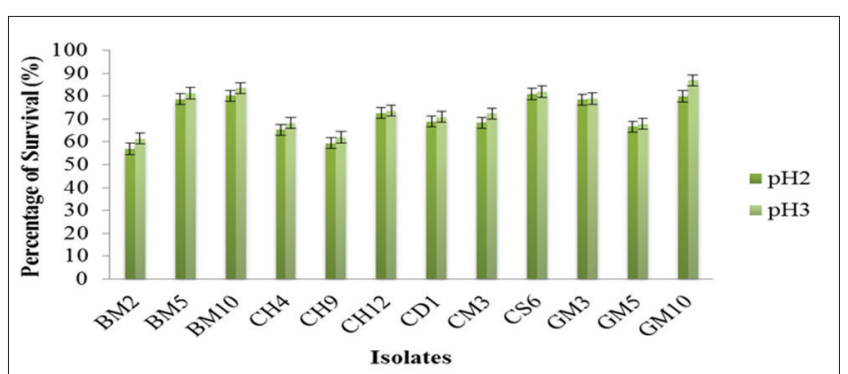

Fig. 2: The survival percentage of lactobacilli isolates in $\mathrm{pH} 2$ and 3

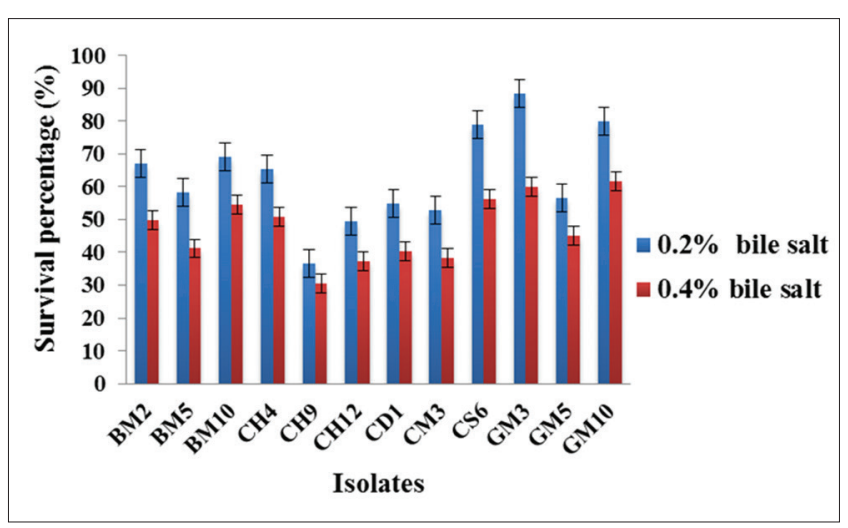

Fig. 3: Survival percentage of lactobacilli isolates in 0.2 and $0.4 \%$ bile salt concentrations

Gelatinase, autoaggregation and coaggregation activities

Among isolated 12 lactobacilli, 8 isolates (BM2, CD1, CH4, CH9, CH12, CS6, BM10 and GM5) exhibited no positive gelatinase activity compared to positive control S. aureus, while 4 isolates (BM5, CM3, GM3 and GM10) exhibited positive gelatinase activity. Adhesive properties are essential for probiotic bacteria, as these provide protection of host mucosal surfaces against entry of pathogens. Aggregation inhibits adherence of pathogen via forming a barrier, which prevents colonization of pathogen thereby limiting their infection [31]. It can also increase the concentration of excreted inhibitory substances [32]. Coaggregation involves the interaction between a Lactobacillus and a pathogenic strain (between genetically different strains) which facilitate direct or indirect clearance of pathogens. Adherence depends on cell surface characteristics. Results (Table 2) exhibited that the GM5 showed maximum and GM3 showed minimum autoaggregation phenotype. The coaggregation of lactobacilli isolates with $E$. coli differs in values ranged from $13.04 \pm 0.21 \%$ to $34.97 \pm 0.37 \%$. The BM5 showed minimum coaggregation ability while it was significantly higher in GM5 (Table 2). Kos et al. [24] reported the relationship between 
Table 2: Autolysis (\%), autoaggregation, coaggregation (\%) and MATS assay of lactobacilli isolates

\begin{tabular}{|c|c|c|c|c|c|c|c|}
\hline \multirow[t]{2}{*}{ Isolates } & \multicolumn{2}{|c|}{ Autolysis (\%) } & \multirow[t]{2}{*}{ Autoaggregation (\%) } & \multirow[t]{2}{*}{ Coaggregation* (\%) } & \multicolumn{3}{|l|}{ MATS (\%) } \\
\hline & After 3 hrs & After 5 hrs & & & Xylene & Toluene & n-hexadecane \\
\hline BM2 & $6.12 \pm 0.12$ & $13.28 \pm 0.57$ & $51.73 \pm 0.98$ & $24.14 \pm 0.34$ & $25.78 \pm 1.32$ & $34.84 \pm 0.21$ & $39.43 \pm 0.80$ \\
\hline BM5 & $20.53 \pm 1.01$ & $32.56 \pm 0.19$ & $34.65 \pm 1.34$ & $13.04 \pm 0.21$ & $21.97 \pm 1.44$ & $41.26 \pm 1.08$ & $46.75 \pm 0.59$ \\
\hline BM10 & $14.20 \pm 0.84$ & $29.35 \pm 0.28$ & $62.34 \pm 1.20$ & $28.75 \pm 1.47$ & $50.10 \pm 2.06$ & $53.70 \pm 0.86$ & $64.84 \pm 1.41$ \\
\hline $\mathrm{CH} 4$ & $10.29 \pm 0.05$ & $16.91 \pm 0.21$ & $46.28 \pm 0.22$ & $18.12 \pm 0.26$ & $38.67 \pm 0.69$ & $25.01 \pm 0.76$ & $50.17 \pm 0.67$ \\
\hline $\mathrm{CH} 9$ & $11.93 \pm 0.10$ & $21.33 \pm 0.98$ & $53.11 \pm 0.83$ & $21.10 \pm 1.65$ & $34.21 \pm 0.39$ & $33.98 \pm 0.48$ & $37.11 \pm 0.03$ \\
\hline $\mathrm{CH} 12$ & $13.04 \pm 0.11$ & $24.67 \pm 0.86$ & $48.18 \pm 1.84$ & $20.33 \pm 0.38$ & $29.34 \pm 0.26$ & $32.45 \pm 0.99$ & $43.09 \pm 0.65$ \\
\hline CD1 & $14.17 \pm 0.33$ & $26.58 \pm 0.70$ & $50.21 \pm 1.56$ & $24.18 \pm 0.06$ & $40.13 \pm 0.14$ & $42.50 \pm 1.37$ & $40.23 \pm 0.52$ \\
\hline CM3 & $21.82 \pm 0.18$ & $40.63 \pm 0.53$ & $49.19 \pm 0.93$ & $19.12 \pm 0.41$ & $34.25 \pm 0.06$ & $39.63 \pm 0.79$ & $45.10 \pm 0.32$ \\
\hline CS6 & $9.27 \pm 0.04$ & $19.53 \pm 0.08$ & $54.90 \pm 1.43$ & $26.36 \pm 0.68$ & $42.78 \pm 2.10$ & $40.00 \pm 0.26$ & $41.05 \pm 0.40$ \\
\hline GM3 & $8.32 \pm 0.16$ & $15.85 \pm 0.13$ & $23.45 \pm 0.78$ & $11.51 \pm 0.50$ & $36.28 \pm 0.89$ & $45.03 \pm 0.45$ & $38.40 \pm 0.18$ \\
\hline GM5 & $17.64 \pm 0.06$ & $30.70 \pm 0.77$ & $67.04 \pm 0.61$ & $34.97 \pm 0.37$ & $40.10 \pm 1.84$ & $38.12 \pm 0.30$ & $42.16 \pm 0.24$ \\
\hline GM10 & $10.75 \pm 0.45$ & $22.34 \pm 0.24$ & $59.03 \pm 1.99$ & $32.62 \pm 1.05$ & $34.03 \pm 1.53$ & $35.51 \pm 0.75$ & $36.60 \pm 0.82$ \\
\hline
\end{tabular}

Values are expressed as the mean \pm standard deviation; $n=3, *$ : Coaggregation of isolates with Escherichia coli MTCC 43, MATS: Microbial adhesion to solvents

autoaggregation and the adhesiveness ability of L. acidophilus M92, which mediated by proteinaceous components on the cell surface. The sedimentation rate of lactobacilli isolates was ranged from $34.65 \pm 1.34 \%$ up to $67.04 \pm 0.61 \%$ over a period of 60 minutes. Recently, Gudina et al. [33] reported a similar and comparative study on Lactobacillus paracasei performed with washed cells suspended in PBS and their own culture supernatant fluid, the autoaggregation observed in both the conditions were similar 51.1 and $49.4 \%$, respectively, after 2 hrs of incubation. In this study, xylene, toluene and n-hexadecane were used, as these solvents are non-polar in nature, their hydrophobic nature help to interact with hydrophobic surfaces of microbes. Lactobacilli with hydrophobic cell surfaces can easily adhere to host epithelium and enhances competition and colonization in the gastrointestinal tract against pathogens.

\section{Microbial adhesion to solvents (MATS)}

Microbial adhesion to $n$-hexadecane is considered as a marker for evaluating adhesiveness of microbial cells [34] and minimum 40\% hydrophobicity is required for a probiotic strain for adhesiveness [35]. In our study, eight out of 12 isolates showed MATS $<40 \%$ and BM10 showed maximum hydrophobicity $(50.10 \pm 2.06 \%, 53.70 \pm 0.86 \%$, and $64.84 \pm 1.41 \%$ ) in xylene, toluene and $n$-hexadecane, respectively (Table 2). Nikolic et al. [36] reported that ten lactobacilli and one Leuconostoc strains showed high adhesion activity to n-hexadecane. L. paracasei subsp. paracasei BGSJ2-8, BGDP1-84 and BGNJ1-61 showed high percentage of adhesion to chloroform and ethyl acetate. Similarly, L. fermentum strains CFR5, CFR1, CFR2 and CFR4 also showed a higher hydrophobicity than the Lactobacillus delbrueckii CFR6, with a maximum value of $53.6 \pm 8.3 \%$ [37].

\section{CONCLUSION}

Probiotic bacteria are beneficial for human health. These can be a perfect replacement of antibiotics. Antibiotics have broad spectrum growth inhibition activity, therefore kill useful flora in gut with the target pathogen while probiotics contain narrow antimicrobial activity. Antibiotics also generate resistance in pathogenic microorganisms. Researches must be proceed to identify and exploitation of new lactobacilli isolates, which fulfill the requirement as probiotic. Keeping ahead a step in this direction, to get potent lactobacilli isolates, in this present study, 141 isolates were isolated from 150 dairy and cattle dung samples. All strains were identified by Gram-staining, catalase test, motility test, and endospore test. 94 isolates were Gram-positive, catalase negative, non-motile and non-sporing in nature. After screening of these lactobacilli isolates, 12 potent probiotic strains with maximum antimicrobial activity were chosen for further study. Out of 12 , two isolates (BM10 and GM10) showed significant results of antimicrobial, probiotic properties and as well as adhesive attributes. The results concluded that these isolates fulfill the requirements of probiotic strains and can be further analyzed for clinical and biotherapeutic applications.

\section{ACKNOWLEDGMENT}

Authors are grateful to Department of Botany, Dr. H. S. Gour (Central) University, Sagar, Madhya Pradesh, for providing necessary facilities to carry out this work and also thanking full to the DST INSPIRE, for providing grant for this work.

\section{REFERENCES}

1. FAO $\backslash$ WHO. Probiotics in Food. Health and Nutritional Properties. FAO Food and Nutrition Paper 85. Rome, Italy: FAO $\backslash$ WHO; 2006.

2. Mishra V, Prasad DN. Application of in vitro methods for selection of Lactobacillus casei strains as potential probiotics. Int J Food Microbiol 2005;103(1):109-15

3. Pakdaman MN, Udani JK, Molina JP, Shahani M. The effects of the DDS-1 strain of Lactobacillus on symptomatic relief for lactose intolerance - A randomized, double-blind, placebo-controlled, crossover clinical trial. Nutr J 2016;15(1):2-11.

4. Amdekar S, Roy P, Singh V, Kumar A, Singh R, Sharma P. Antiinflammatory activity of lactobacillus on carrageenan-induced paw edema in male wistar rats. Int J Inflam 2012;2012:752015.

5. Bouhafs L, Moudiloub EN, Exbrayat JM, Lahouel M, Idouiad T. Protective effects of probiotic Lactobacillus plantarum BJ0021 on liver and kidney oxidative stress and apoptosis induced by endosulfan in pregnant rats. Ren Fail 2015;37(8):1370-8.

6. Dilna SV, Surya H, Aswathy RG, Varsha KK, Sakthikumar DN, Pandey A, et al. Characterization of an exopolysaccharide with potential health benefits properties from a probiotic Lactobacillus plantarum RJF4. Food Sci Technol 2015;64:1179-86.

7. Gaon D, Garmendia C, Murrielo NO, Games AD, Cerchio A, Quintas R, et al. Effect of Lactobacillus strains (L. casei and L. acidophilus strains cereal) on bacterial overgrowth-related chronic diarrhea. Medicina 2002;62:159-63.

8. Kaewnopparat S, Dangmanee N, Kaewnopparat N, Srichana T, Chulasiri M, Settharaksa S. In vitro probiotic properties of Lactobacillus fermentum SK5 isolated from vagina of a healthy woman. Anaerobe 2013;22:6-13

9. Bejar W, Hamden K, Ben Salah R, Chouayekh H. Lactobacillus plantarum TN627 significantly reduces complications of alloxaninduced diabetes in rats. Anaerobe 2013;24:4-11.

10. Liu CF, Tung YT, Wu CL, Lee BH, Hsu WH, Pan TM. Antihypertensive effects of Lactobacillus-fermented milk orally administered to spontaneously hypertensive rats. J Agric Food Chem 2011;59(9):4537-43.

11. Lee HY, Park JH, Seok SH, Baek MW, Kim DJ, Lee KE, et al. Human originated bacteria, Lactobacillus rhamnosus PL60, produce conjugated linoleic acid and show anti-obesity effects in diet-induced obese mice. Biochim Biophys Acta 2006;1761(7):736-44.

12. Narva M, Collin M, Lamberg-Allardt C, Kärkkäinen M, Poussa T, Vapaatalo $\mathrm{H}$, et al. Effects of long-term intervention with Lactobacillus helveticus-fermented milk on bone mineral density and bone mineral content in growing rats. Ann Nutr Metab 2004;48(4):228-34.

13. Deegan LH, Cotter PD, Hill C, Ross P. Bacteriocins: Biological tools for bio-preservation and shelf-life extension. Int Dairy J 2006;16:1058-71.

14. Grajek K, Sip A, Foksowicz-Flaczyk J, Dobrowolska A, Wita A. Adhesive and hydrophobic properties of the selected LAB isolated 
from gastrointestinal tract of farming animals. Acta Biochim Pol 2016;63(2):311-4.

15. Wen LS, Philip K, Ajam N. Purification, characterization and mode of action of plantaricin K25 produced by Lactobacillus plantarum. Food Control 2015;60:430-9.

16. Fong FL, Kirjavainen P, Wong VH, Nezami HE. Immunomodulatory effects of Lactobacillus rhamnosus GG on dendritic cells, macrophages and monocytes from healthy donors. J Funct Foods 2015;13:71-9.

17. Hartemink R, Domenech VR, Rombouts FM. LAMVAB - A new selective medium for the isolation of lactobacilli from faeces. J Microbiol Methods 1997;29(2):77-84.

18. Esayas A, Fekadu B, Amutha S. Isolation and characterization of inhibitory substance producing lactic acid bacteria from Ergo, Ethiopian traditional fermented milk. Livest Res Rural Dev 2008;20:1-8.

19. Sieladie DV, Zambou NF, Kaktcham PM, Cresci A, Fonteh F. Probiotic properties of Lactobacilli strains isolated from raw cow milk in the western highlands of Cameroon. Innov Rom Food Biotechnol 2011;9:12-28

20. Dora IA, Glenn RG. Cholesterol assimilation by lactic acid bacteria and bifidobacteria isolated from the human gut. Appl Environ Microbiol 2002;68(9):4689-93.

21. Harrigan WF, McCance ME. Laboratory Methods in Food and Dairy Microbiology. London: Academic Press; 1990.

22. Basson A, Flemming LA, Chenia HY. Evaluation of adherence, hydrophobicity, aggregation, and biofilm development of Flavobacterium johnsoniae-like isolates. Microb Ecol 2008;55(1):1-14.

23. Saran S, Bisht MS, Singh K, Teotia UV. Compare adhesion attributes of two isolates of Lactobacillus acidophilus for assessment of prebiotics, honey and inulin. Int J Sci Res Publ 2012;2(4):1-7.

24. Kos B, Suskovic J, Vukovic S, Simpraga M, Frece J, Matosic S. Adhesion and aggregation ability of probiotic strain Lactobacillus acidophilus M92. J Appl Microbiol 2003;94:981-7.

25. Mohanty D, Saini MR, Mohapatra S. In vitro study on release of bioactive antimicrobial compounds from dairy products by certain promising probiotic Lactobacillus strains. Int J Pharm Pharm Sci 2017:9:2-6.

26. Singh TP, Kaur G, Malik RK, Schillinger U, Guigas C, Kapila S. Characterization of intestinal Lactobacillus reuteri strains as potential probiotics. Probiotics Antimicrob Proteins 2012;4:47-58.

27. Haung Y, Adams MC. In vitro assessment of the upper gastrointestinal tolerance of potential probiotic dairy propionic bacteria. Int J Food Microbiol 2004;91(3):253-60.

28. Mohanty D, Ray P. Evaluation of probiotic and antimicrobial properties of Lactobacillus strains isolated from dairy products. Int J Pharm Pharm Sci 2016;8(11):230-4

29. Prabhurajeshwar C, Kelmani CR. Development of in vitro methodologies for inhibition of pathogenic bacteria by potential probiotic Lactobacillus sps; An evidence for production of antimicrobial substances. Int J Pharm Pharm Sci 2016;8(12):277-86.

30. Koch S, Eugster-Meier E, Oberson G, Meile L, Lacroix C. Effects of strains and growth conditions on autolytic activity and survival to freezing and lyophilization of Lactobacillus delbrueckii ssp. Lactis isolated from cheese. Int Dairy J 2007;18(2):187-96.

31. García-Cayuela T, Korany, AM, Bustos I, de Cadiñanos LP, Requena T, Peláez C, et al. Adhesion abilities of dairy Lactobacillus plantarum strains showing an aggregation phenotype. Food Res Int 2014;57:44-50.

32. Kruisselbrink A, Bak-Glashouwer MJ, Havenith CE, Thole JE, Janssen R. Recombinant Lactobacillus plantarum inhibits house dust mite-specific T-cell responses. Clin Exp Immunol 2001;126(1):2-8.

33. Gudina EJ, Teixeira JA, Rodrigues LR. Isolation and functional characterization of a biosurfactant produced by Lactobacillus paracasei. Colloids Surf B Biointerfaces 2010;76(1):298-304.

34. Kiely LJ, Olson NF. The physicochemical surface characteristics of Lactobacillus casei. Food Microbiol 2000;17(3):277-91.

35. Del Re B, Sgorbati B, Miglioli M, Palenzola D. Adhesion, autoaggregation and hydrophobicity of 13 strains of Bifidobacterium longum. Lett Appl Microbiol 2000;31(6):438-42.

36. Nikolic M, Jovcic B, Kojic M, Topisirovic L. Surface properties of Lactobacillus and Leuconostoc isolates from homemade cheeses showing auto-aggregation ability. Eur Food Res Technol 2010;231(6):925-31.

37. Palaniswamy SK, Govindaswamy V. In-vitro probiotic characteristics assessment of feruloyl esterase and glutamate decarboxylase producing Lactobacillus spp. Isolated from traditional fermented millet porridge (kambu koozh). LWT Food Sci Technol 2016;68:208-16. 